\title{
Distribution of Members of the Anopheles Gamibiae s.l. In Oyo State, South West Nigeria
}

\author{
Adedapo O. Adeogun ${ }^{1,2}$, Kehinde O.K. Popoola ${ }^{3}$, Abiodun K. Olakiigbe ${ }^{1}$, Samson T. \\ Awolola ${ }^{1}$ \\ ${ }^{1}$ Molecular Entomology and Vector Control Research Laboratory, Public Health and Epidemi- \\ ology Department, Nigerian Institute of Medical Research, Yaba, Lagos, Nigeria \\ ${ }^{2}$ Department of Biological Sciences, Lead City University, Ibadan \\ 3Department of Zoology, University of Ibadan, Ibadan, Nigeria
}

*Correspondence should be addressed to Adedapo O. Adeogun : dapoadeogun@hotmail.com

Received 05 May 2019; Revised 30 September 2019; Accepted o3 October 2019

(C) 2019 Adeogun et al. Licensee Pan African Journal of Life Sciences. This is an Open Access article distributed under the terms of the Creative commons Attribution License (https://creativecommons.org/licenses/BY/4.o), which permits unrestricted use, distribution, and reproduction in any medium, provided the original work is properly cited.

Background: Members of the Anopheles gambiae s.l. remain the most efficient vectors of malaria parasite in Africa. However, for timely and effective vector control activities, the distribution of these important vectors in local communities is crucial. We therefore determine the distribution of the members of Anopheles gambiae s.l. in Oyo State, Nigeria

Methods: Larval stages of Anopheles mosquitoes were collected from identified mosquito breeding sites in six localities (Oluyole, Eruwa, Oyo, Ojoo, Bodija, and Ogbomoso) in Oyo State and reared to adults. Three to five days old adult emergence were identified morphologically using standard methods. A total of 100 mosquitoes were selected from each of localities for molecular analysis. DNA were extracted and Polymerase Chain Reaction (PCR-ID) followed by restriction endonucleases digestion was used for molecular identification.

Results: A total of 58 larval breeding sites were sampled out of which 12 (20.7\%) had Anophelines only, 21 (36.2\%) contained Culicines only and the remaining $25(43.1 \%)$ had both Anophelines and Culicines. The mosquitoes were mostly found in footprints, followed by tire tracks, pools, puddle and ponds. The habitat type distribution for Anopheline and Culicines were not different $\left(X^{2}=5.25, D F=5, P>0.01\right)$. A total of 1,725 Anophelines emerged from the collection out of which, 823 were females. All the female samples were morphologically identified as members of the Anopheles gambiae s.l.. A total of 600 (72.9\%) of the female Anopheline population was subjected to PCR. PCR-ID showed that the mosquito populations contained higher numbers of Anopheles arabiensis (58\%) than Anopheles gambiae s.s. (42\%). Enzyme digest indicate that samples from Oluyole, Iwo road and Bodija were manly the M form (now called An. coluzzii), while both M (An. colizzii) and S (An. gambiae) form occur in sympatry in Oyo town and Eruwa.

Conclusion: This study presents information on the distribution of Anopheles arabiensis, Anopheles coluzzii and Anopheles gambiae in Oyo State. This has implication on the vector control activities in the State as members of these Anopheles mosquitoes exhibit varying feeding behaviours, transmission pattern and resistance profiles. Such information is useful in planning vector control activities for the State

Keywords: Distribution, Anopheles gambiae s.l., Anopheles coluzzii, Anopheles arabiensis, Anopheles gambiae 


\section{1.o INTRODUCTION}

Malaria remain a serious public health disease in Nigeria accounting for $60 \%$ of outpatients visits and up to $30 \%$ of hospitalizations among children under five years of age [1]. Up to $85 \%$ of Nigerians live in areas supporting mesoendemic malaria transmission, $15 \%$ lived under conditions of hyper- holoendemicity while areas within Abuja, Adamawa and Borno states support hypoendemicity [2]. With an estimated population of 160 million and zonal variations ranging from $27.6 \%$ in the South-east to $50.3 \%$ in the South-west, the country has a large population at risk. The dominant species of malaria parasite in Nigeria is Plasmodium falciparum which accounts for up to $95 \%$ of the malaria cases and the most pathogenic of the five human malaria parasites [2]. Plasmodium falciparum have also been found to occur with other plasmodium species like $P$. malariae and $P$. ovale in Nigeria [3].

The transmission of malaria parasite depends largely on the availability of competent mosquito vectors [4]. In Nigeria, the primary malaria vectors include species in the Anopheles gambiae complex (including An. gambiae, An. coluzzii and An. arabiensis) and Anopheles funestus group. These species are widely distributed across the country, from the mangrove and coastal areas of the South to the Sahel savannah of the North. An. gambiae s.s., An. arabiensis, and An. coluzzii typically breeds in sunlit, shallow and temporary fresh water bodies such as ground depressions, puddles, pools and hoof prints. An. funestus breeds in permanent or semi-permanent body of fresh water with emergent vegetation which sustains malaria transmission during the dry season [2].

Anopheles coluzzii and An. gambiae are highly anthropophilic and endophilic with sporozoite rates ranging from 0.2-11.8\%. Anopheles arabiensis and An. funestus are zoophilic and anthropophilic, with sporozoite rate of $0-4.8 \%$ and $1.2-2.3 \%$ respectively [2]. In most cases, sporozoite infection in the wet season are maintained by An. gambiae s.s. and An. coluzzii while An. arabiensis maintains transmission in the dry season [5]. Transmission indices show that the entomological inoculation rates (EIR) range from 18-145 infective bites per year for An. coluzzii and An. gambiae s.s. in the North central and 12-54 infective bites per year for An. funestus in the South west. The EIR estimated for An. arabiensis ranged between 0-12.4 [2].

One of the principal strategies for preventing and controlling malaria transmission vis-à-vis reduction in mosquito population is vector control [2]. Therefore, mapping the distribution of vectors and understanding their behaviour is essential in planning vector control activities. However, there is paucity of data on the distribution of the major malaria vectors in Nigeria [2]. It is therefore important that reports are made available on the distribution of sibling species in space and time to inform specific vector control strategies against the malaria vectors. This study therefore examine the distribution of the major malaria vectors in Nigeria.

\section{2.o METHODOLOGY}

\subsection{Study area}

The study was carried out in Oyo State, Southwest, Nigeria. Oyo state lies between longitude $8^{\circ} \mathrm{Oo}^{\prime} \mathrm{N}$ and latitude $4^{\circ} \mathrm{Oo}^{\prime} \mathrm{E}$ and has a total land mass of $28,454 \mathrm{~km}^{2}(10,986.2 \mathrm{sq} \mathrm{mi})$. It is bounded partly by Ogun State in the South and Kwara State in the North. To the West, it is bounded partly by Ogun State and partly by the Republic of Benin, while in the East it is bounded by Osun. The topography of the State is one of the gentle rolling lowland in the south, rising to a plateau 40 metres and above in the North. The vegetation pattern of the State is that of rain forest in the South and guinea savannah to the North. Thick forest in the South gives way to grassland interspersed with trees in the north. Agriculture is the main occupation as the climate in the State favors the cultivation of crops like maize, yam, cassava, millet, rice, plantains, cocoa, palm produce, cashew [6].

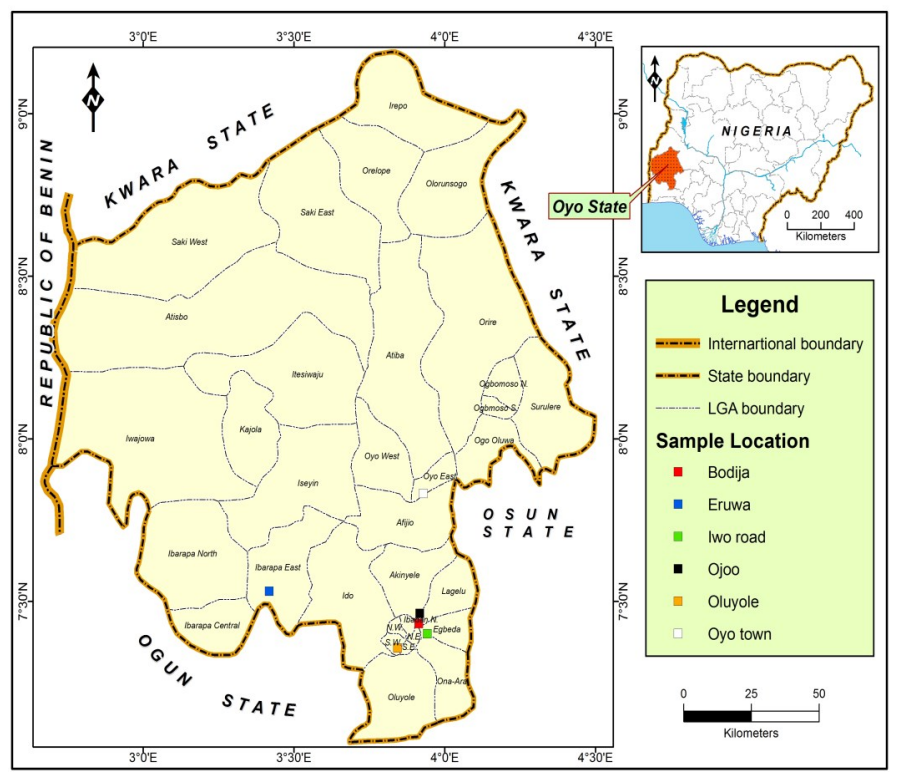

Figure 1: Map of Oyo State showing the collection points 


\subsection{Mosquito Larval Collection and Rearing}

Anopheles mosquitoes were identified from six localities (Oluyole, Eruwa, Oyo, Ojoo, Bodija and Ogbomoso) in Oyo state (Fig. 1). Identified breeding sites were mapped with Garmin eTrex ${ }^{\circledR}$ GPS 10 personal navigator. Following a standard protocol [7], larval samples were collected by lowering white dippers gently into identified breeding sites at an angle of 450 to the surface until one side is just below the surface. These were moved along the breeding site, skimming the surface of the water with the dipper and raised out of the water, making sure that the water containing the larvae and pupa does not spill. The larval and pupal samples were transferred into collection bottles, properly labelled per locality and taken to the Molecular Entomology and Vector Control Research laboratory of the Nigerian Institute of Medical Research, Yaba, Lagos. Upon arrival at the insectary, larval samples, kept in larval bowls, were maintained under standard insectary conditions $\left(25^{-2} 8^{\circ} \mathrm{C}\right.$ and $\sim 70-$ $80 \%$ humidity, with a $12 \mathrm{hr}$ day/night cycle) [8] and fed with yeast daily. Adult emergence were fed with $10 \%$ glucose solution (with cotton wool soaked in water containing $10 \%$ sugar solution and placed inside the cage).

\subsection{Morphological Identification of Mosquito species}

The adult emergence were identified morphologically with the aid of Gilles and Coetzee [9] identification guide. Anopheline mosquitoes was identified with their speckled legs, hind tarsus 4-5 entirely pale, abdominal segments without laterally projecting tufts of scales, 3 bands on the palps, 3rd main dark area (preapical dark spot) of vein 1 with pale interruption, sometimes fused with the preceding pale spot and scaling on abdomen very scanty often confined to 8 th or rarely 7 th terga belonged to the An. gambiae s.l.. Upon proper morphological Identification, mosquitoes belonging to this complex were further identified using Polymerase Chain Reaction (PCR) technique.

\subsection{Molecular Identification of Mosquito species}

One hundred morphologically identified An. gambiae s.l. were selected from each locality for molecular identification. DNA extraction was conducted with the aid of a genomic DNA extraction kit prepGEMTM insect (ZyGEM Corporation Limited, New Zealand). DNA was also extracted from the positive controls available at the Molecular Entomology and Vector Control unit, Nigerian Institute of Medical Research, Lagos. $1 \mu \mathrm{l}$ of the DNA was used as template for the PCR. For the species identification of An. gambiae complex, a standard protocol was adopted
[10]. Master mix solution containing 2.5 $\mu$ l of 10x PCR reaction buffer, $2.5 \mu \mathrm{l}$ of dNTP, $1 \mu \mathrm{l}$ of MgCL solution, $1 \mu \mathrm{l}$ of An. quadriannulatus primer, $2 \mu \mathrm{l}$ each of the other primers (Universal, An. gambiae s.s., An. arabiensis, An. merus/melas), $4.9 \mu \mathrm{l}$ of sterile distilled water and $0.2 \mu \mathrm{l}$ Taq polymerase enzyme. The PCR conditions include $94^{\circ} \mathrm{C}$ for $2 \mathrm{~min}$ (denaturation phase), 30 cycles of $940 \mathrm{C}$ for 30 seconds, $50^{\circ} \mathrm{C}$ for 30 seconds, and $72^{\circ} \mathrm{C}$ for $30 \mathrm{sec}-$ onds (Hybridization and Extension phase), and a final extension phase of $72^{\circ} \mathrm{C}$ for $5 \mathrm{~min}$. 12.5 $\mu$ l reaction volume of the product was electrophoresed in 2.5\% SEAKEM ${ }^{\circledR}$ agarose gel containing ethidium bromide and photographed under ultraviolet light illuminator. Anopheles gambiae s.s. present in the population were further identified as An. coluzzii and An. gambiae using restriction endonuclease. $12.5 \mu \mathrm{l}$ of the PCR product was digested by adding, $2 \mu \mathrm{l}$ of Heamophilus haemolyticus (HhaI) restriction enzyme, $18 \mu \mathrm{l}$ of distilled water, and $2 \mu \mathrm{l}$ of 10x Buffer Tango ${ }^{\mathrm{TM}}$. Reaction mixture was incubated for 4 hours at $37^{\circ} \mathrm{C}$ as previously described [11]. The reaction was stopped by adding $2 \mu \mathrm{l}$ of $0.5 \mathrm{M}$ EDTA. The entire product was electrophoresed in 2.5\% SEAKEM $^{\circledR}$ agarose gel containing ethidium bromide and photographed under ultraviolet light illuminator.

\subsection{Data Analysis}

Data was analysed with SPSS version 23.0. Habitat preference of Anophelines and Culicines were subjected to chi-square distribution. Percentage occurrence of Anopheline only, Culicine only and presence of Anopheline and Culicine was also calculated. For species identification, percentage occurrence of each species was calculated.

\subsection{RESULTS}

\subsection{Larval Habitat Type and Habitat Preference}

The A total of 58 mosquito larval habitats were sampled (Table 1) out of which 12 breeding sites contained anopheline only, 25 contained culicines only while the remaining 21 had a mixture of culicines and anophelines. Larval habitat preference was heterogeneous across the sites. Anopheline mosquitoes were found in puddles and tire tracks, while cilucines were found in footprints, pools, puddle, and tire tracks. Both anophelines and culicines were found in footprints, ponds, and puddles (Table 1). The breeding site distribution for habitats with anopheline only or culicine only larvae was not different (Table $1 ; \chi^{2}=5.25$, degree of freedom $[\mathrm{df}]=5, \mathrm{P}>0.01$ ). 
Table 1.Distribution and abundance of Anopheline and Culicine mosquito larvae in 58 aquatic habitats.

\begin{tabular}{lllll}
\hline $\begin{array}{l}\text { Larval } \\
\text { habitat } \\
\text { type }\end{array}$ & $\begin{array}{l}\text { Anophe- } \\
\text { line larva }\end{array}$ & $\begin{array}{l}\text { Culicine } \\
\text { larva }\end{array}$ & $\begin{array}{l}\text { Anopheline } \\
\text { and Culicine } \\
\text { larva }\end{array}$ & Total \\
\hline Footprints & 0 & 17 & 9 & 26 \\
Ponds & 0 & 2 & 0 & 2 \\
Pool & 0 & 0 & 11 & 11 \\
Puddle & 3 & 2 & 1 & 6 \\
Tire tracks & 9 & 0 & 4 & 13 \\
Tanks & 0 & 0 & 0 & 0 \\
Total & $12(20.7 \%)$ & 21 & $25(43.1 \%)$ & 58 \\
& & $(36.2 \%)$ & & \\
\hline
\end{tabular}

\subsection{Abundance and Distribution of Members of the Anopheles gambiae s.l. Across the Six Sites}

A total of 600 An. gambiae s.l. (100 per site) were further identified using PCR (Table 1, Figure 2, Plate 1). The remaining specimens could not be identified due to lack of PCR products. In total, An. gambiae s.s. and An. arabiensis were the only members of the An. gambiae complex found across all sites. On the average, An. arabiensis (58\%) was more abundant than An. gambiae s.s. (42\%). There were more An. gambiae s.s. found in the population from Oluyole (87\% An. gambiae s.s. vs. $13 \%$ An. arabiensis), Oyo town (73\% An. gambiae s.s. vs. $27 \%$ An. arabiensis) and Eruwa (53\% An. gambiae s.s. vs. 47\% An. arabiensis) (Table 2), while the population from Iwo road and Bodija contained more An. arabiensis than An. gambiae s.s. However, all the mosquitoes analysed from Ojoo samples were An. arabiensis (Table 2).

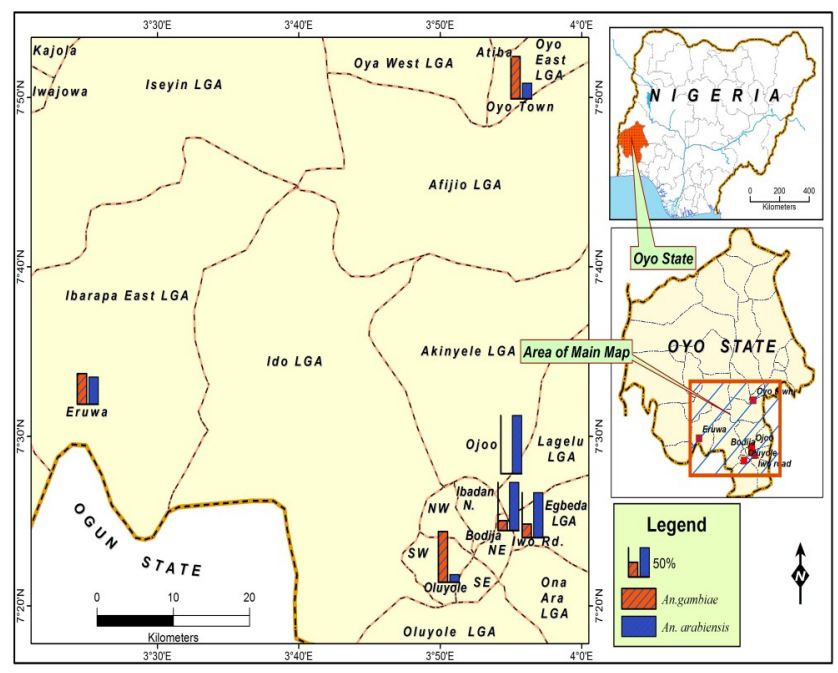

Figure 2. Abundance and Distribution of the members of Anopheles gambiae complex identified from the six localities sampled in Oyo State

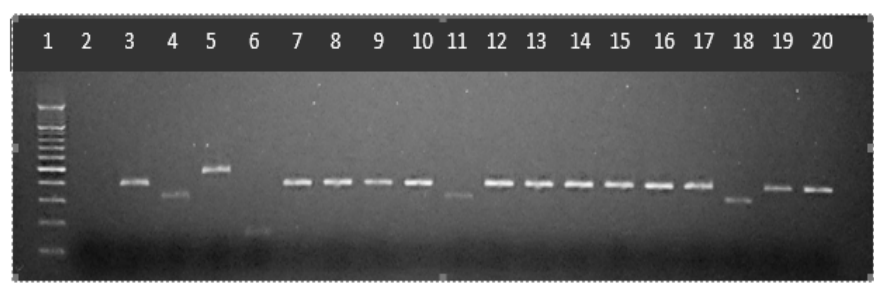

Plate 1: Polymerase Chain Reaction Gel electro gram of some of the field collected samples.

Lane 1 - Ladder/Marker; Lane 2- negative control; Lane 3-6 - positive controls (An. gambiae s.s., An. arabiensis, An. melas/merus, An. quadriannulatus respectively); Lane 7-10, 1217, 19, 20 - field samples (An. gambiae s.s.); Lane 11 and 18 field samples (An. arabiensis).

Table 2. Distribution of members of An. gambiae complex and An. gambiae s.s. molecular forms in the studied localities

\begin{tabular}{|c|c|c|c|c|c|c|}
\hline \multirow[t]{3}{*}{ State } & \multirow[t]{3}{*}{$\begin{array}{l}\text { Locali- } \\
\text { ties }\end{array}$} & \multirow[t]{3}{*}{$\begin{array}{l}\text { No. ex- } \\
\text { amined }\end{array}$} & \multicolumn{2}{|c|}{$\begin{array}{l}\text { PCR - Species Iden- } \\
\text { tification }\end{array}$} & \multicolumn{2}{|c|}{$\overline{\text { PCR - Form }}$} \\
\hline & & & $\begin{array}{l}\% A n . \\
\text { gambiae }\end{array}$ & $\begin{array}{l}\text { \%An. } \\
\text { arabiensis }\end{array}$ & \%"S" & \% "M" \\
\hline & & & s.s. & & & \\
\hline \multirow[t]{7}{*}{ Oyo } & Oluyole & 100 & $87 \%$ & $13 \%$ & & $100 \%$ \\
\hline & Iwo road & 100 & $23 \%$ & $77 \%$ & - & $100 \%$ \\
\hline & Bodija & 100 & $17 \%$ & $83 \%$ & - & $100 \%$ \\
\hline & Ojoo & 100 & - & $100 \%$ & - & - \\
\hline & Oyo town & 100 & $73 \%$ & $27 \%$ & $5 \%$ & $95 \%$ \\
\hline & Eruwa & 100 & $53 \%$ & $47 \%$ & $50 \%$ & $50 \%$ \\
\hline & Total & 600 & $42 \%$ & $58 \%$ & & \\
\hline
\end{tabular}

\subsection{Abundance and Distribution of Members of the Anopheles gambiae s.s. (An. gambiae and An. coluzzii) across the six sites}

Only the An. gambiae s.s. in the populations were analysed for PCR-form using restriction digest (Plate 2). Oluyole, Iwo road and Bobija population contained purely An. coluzzii (M molecular form) while the population from Oyo town and Eruwa had sympatric occurrence of An. gambiae and An. coluzzii (Table 2, Figure 3, Plate 2). Oyo town contained more $A n$. coluzzii than An. gambiae (95\% An. coluzzii vs. 5\% An. gambiae) but there was equal abundance of both species in Eruwa (50\% An. coluzzii vs. 50\% An. gambiae) (Table 2). However, samples from Ojoo were not analysed for these species because they were mainly An. arabiensis. 


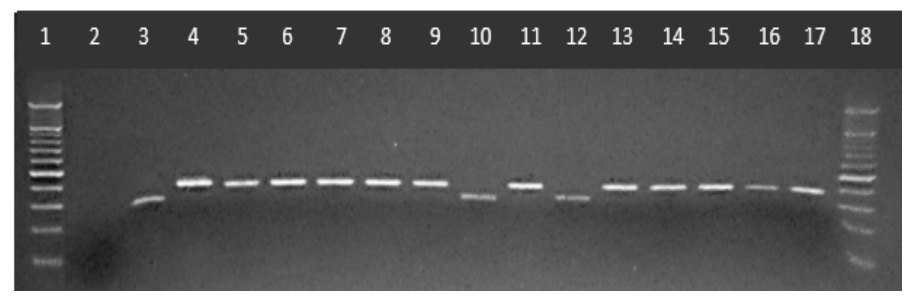

Plate 2: Gel electro gram of some of the Molecular digest (M and S form) of PCR products of An. gambiae s.s.

Lane 1 and 18 -Ladder/Marker; Lane 2- negative control; Lane 3- positive control (An. gambiae s.s.); Lane 4- positive control M form (An. coluzzii); Lane 5-9, 11, 13-17 - Field samples M form (An. coluzzii); Lane 10 and 12 - field samples (An. gambiae s.s.)

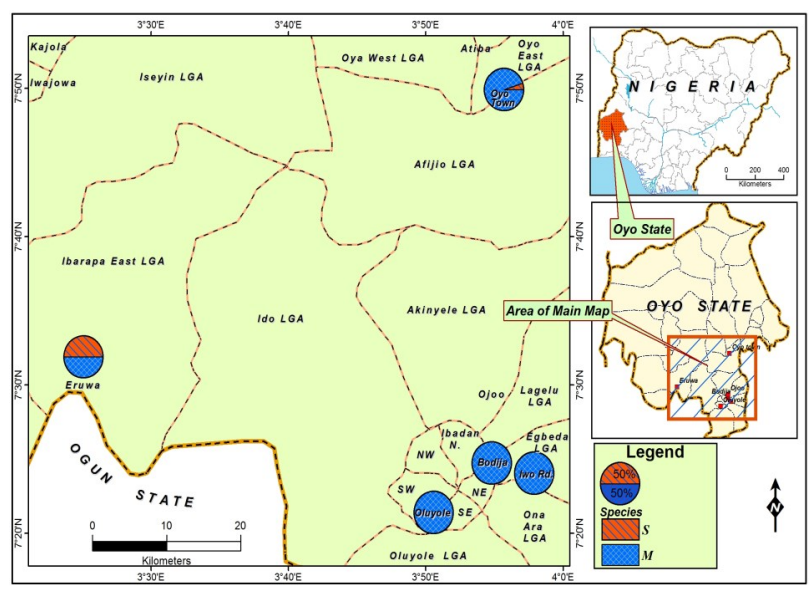

Figure 3. Abundance and Distribution of the members of Anopheles gambiae s.s. (Anopheles coluzzii "M form" and Anopheles gambiae "S form) identified from the localities sampled in Oyo State

\subsection{DISCUSSION}

Although, this study did not examine the influence of environmental variables on larval site preference, it seem Anophelines and Cilucines larva primarily breed and coexist freely in most of the habitats examined as the study did not detect any statistically significant associations between breeding site preference and mosquito occurrence and abundance. This study provide data on the distribution of Anopheline mosquitoes in some parts of Oyo State. Larval habitat preference was highly heterogenous for Anophelines and Culicines across the sites sampled. However, this study did not identify the possible environmental variables that determine anopheline occurrence and abundance in relation to larval habitats. This is because the heterogeneity in An. gambiae s.l. species composition has been reported to be affected either by many variables, each of which has a small effect, or by other important variables that have not yet been measured under field conditions [12]. This is also consistent with the results of Robert et al [13] who found that the occurrence and abundance of one of the major malaria vectors, $A n$. arabiensis larvae in permanent habitats in Dakar, Senegal, are determined by many physicochemical and biological variables.

Malaria vector control either by Indoor Residual Spray (IRS), Long Lasting Insecticide Treated Nets (LLINs) or genetic control strategies requires accurate mosquito identification and information on the behaviour of vector species which informs the choice of control strategies to deploy. Although the distribution of members of the $A n$. gambiae is well documented in Africa [9], much of the work is still not well documented in Nigeria. Most of the work conducted in Nigeria focused on the dynamics and insecticide resistance status of the malaria vectors $[5,14-$ 19]. However, there has been less emphasis on the distribution of these important vectors especially in the studied localities [14, 20, and 21].

There has been no report showing the distribution of these malaria vectors in Oyo State. Data available are that of spot checks involving samples exposed to insecticides [14, 22]. Our map shows the sympatric occurrence of $A n$. gambiae s.s. and An. arabiensis across all sites examined with the absence of other species of Anopheles. The paucity of data from these areas affirms the presence of both species of Anopheles as detected in this study. This would serve as a guide for vector control activities in these localities. The dominance of the $\mathrm{M}$ molecular form (now An. coluzzii) in the Anopheles gambiae s.s. populations reported from Oluyole, Iwo road, Bodija and Oyo town is not surprising and may be due to the greater adaptive features of the $\mathrm{M}$ form as compared with the $\mathrm{S}$ (now also called An. gambiae) [23,24]. Both An. coluzzii and An. gambiae occur in sympatry at Oyo town and Eruwa. The presence of these molecular forms in our study confirms the earlier reports by Awolola [14] on the presence of the two molecular forms in certain parts of South west Nigeria. However, our report is the first to present the presence of An. coluzzii and An. gambiae occurring in sympatry from Oyo state populations.

Our map suggests the absence of An. gambiae s.s. in Ojoo. This is in contract to an earlier report [22]. The disparity in the data may be attributed to the method of collection and the low number of Anopheles mosquitoes tested by PCR in earlier studies from this locality. Up to date, there is no spatially- continuous map of Anopheles mosquitoes from the selected localities. Our introduced approach, however, yielded more finely resolved $A n$. gambiae s.l. distribution in Oyo state. 
These data provide valuable information for selective and targeted malaria vector control in some parts of Oyo State. The maps may also be useful for planning future implementation of malaria control by genetically manipulated mosquitoes. In addition, temporal distribution maps of the molecular forms would be useful especially in areas where they occur in sympatry [24,25].

This study represents a continuous distribution map of the members of An. gambiae s.s. in Oyo State, Nigeria. The study provide valuable information for selective vector control in the state and may serve as a decision support tool for future malaria control strategies including genetically manipulated mosquitoes in the areas.

\section{Conflict of interest}

Authors declare that there is no conflict of interest

\section{Authors' Contributions}

AOA conceived and designed the study,collected data, contributed to data analysis and revised the manuscript. KOKP performed study design, drafted the manuscript and contributed data analysis. AKO performed data analysis. STA conceived and performed study design. All authors approved the final manuscript.

\section{Acknowledgement}

We thank Prof. Adekunle Bakare of the Department of Zoology, Faculty of Science, University of Ibadan, for his assistance during the preliminary stages of this work.

\section{References}

1. Ibrahim KT, Popoola KO, Adewuyi OR, Adeogun AO, Oricha AK. Susceptibility of Anopheles gambiae sensu lacto (Diptera: Culicidae) to Permethrin, Deltamethrin and Bendiocarb in Ibadan City, Southwest Nigeria. Current Research Journal of Biological Sciences. 2013; 5(2): 42-48.

2. Federal Ministry of Health $(\mathrm{FMoH})$. National Malaria Strategic Plan 2014-2020. 14-17.

3. World Health Organization: World Malaria Report. In WHO Global Malaria Programme. Geneva, Switzerland. 2012.

4. Omumbo J, Rapuoda JO, Le Sueur MHC, Snow RW. Mapping malaria transmission intensity using geographical information systems (GIS): an example from Kenya. Ann. Trop. Med. Parasitol. 1998; 92: 7-21.

5. PMI President Malaria Initiative. AIRS Nigeria Final Entomology Report. 2014.

6. Official website of the Oyo State Government, 2019. https://oyostate.gov.ng/about-oyo-state/

7. Service MW. Studies on sampling larval population of Anopheles gambiae complex. Bull WHO. 1971; 45: 169-80.
8. Das S, Garver L, Dimopoulus G. Protocol for mosquito rearing (An. gambiae). J. Vis Exp. 2007; 5:221.

9. Gillies MT., Coetzee M. A supplement to the Anophelinae of Africa south of the Sahara (Afrotropical region). Publications of the South African Institute for Medical Research. 1987; no. 55 .

10. Scott JA, Brogdon WG, Collins FH. Identification of single specimens of the Anopheles gambiae complex by the polymerase chain reaction. American Journal of Tropical Medicine and Hygiene. 1993; 49: 520-529.

11. Favia G, della Torre A, Bagayoko M, Lanfrancotti A, Sagnon N'F, Toure YT, Coluzzi M. Molecular identification of sympatric chromosomal forms of Anopheles gambiae and further evidence of their reproductive isolation. Insect Molecular Biology. 1997; 6 (4): 377-383.

12. Minakawa N, Mutero CM, Githure JI, Beier JC, Yan G. Spatial distribution and habitat characterisation of anopheline mosquito larvae in western Kenya. American Journal of Tropical Medicine and Hygiene. 1999; 61 (6): 1010-1016.

13. Robert V, Awono-Ambene HP, Thioulouse J. Ecology of larval mosquitoes, with special reference Anopheles arabiensis (Diptera: Culicidae) in market-garden wells in urban Dakar, Senegal. Journal of Medical Entomology.1998; 35: 948-955.

14. Awolola TS, Oyewole IO, Amajoh CN, Idowu ET, Ajayi MB, Oduola AO, Manafa OU, Ibrahim K, Koekemoer LL, Coetzee M. Distribution of the molecular $\mathrm{M}$ and $\mathrm{S}$ forms of Anopheles gambiae and pyrethroid knockdown resistance gene in Nigeria. Acta Tropica. 2005; 95: 204-209.

15. Awolola TS, Oduola AO, Oyewole IO, Obansa JB, Amajoh CN, Koekemoer LL, Coetzee M. Dynamics of knockdown pyrethroid insecticide resistance alleles in a field population of Anopheles gambiae in Southwestern Nigeria. Journal of Vector Borne Diseases. 2007; 44: 181-188.

16. Oduola AO, Olojede JB, Ashiegbu CO, Adeogun AO, Otubanjo OA, Awolola TS. High level of DDT resistance in the malaria mosquito: Anopheles gambiae s.l. from rural, semi urban and urban communities in Nigeria. Journal of Rural Tropical Public Health. 2010; 9: 114-120

17. Oduola AO, Idowu ET, Oyebola MK, Adeogun AO, Olojede JB, Otubanjo OA, Awolola TS. Evidence of carbamate resistance in urban populations of Anopheles gambiae s.s. mosquitoes resistant to DDT and deltamethrin insecticides in Lagos, South-Western Nigeria. Parasites and Vectors. 2012; 5: 116.

18. Awolola TS, Oduola OA, Strod C, Koekemoer LL, Brooke DB, Ranson H. Evidence of multiple pyrethroid resistance mechanisms in the malaria vector Anopheles gambiae sesu stricto from Nigeria. Transactions of the Royal Society of Tropical Medicine and Hygiene. 2008; 103(11): 1139-45.

19. Adeogun AO, Popoola KOK, Oduola AO, Olakiigbe AK, Awolola TS. High level of DDT resistance and Reduced susceptibility to Deltamethrin in Anopheles gambiae, Anophe- 
les coluzzi, and Anopheles arabiensis from Urban communities in Oyo State, South-West Nigeria. Journal of Mosquito Research. 2017; 7: 125-33.

20. Awolola TS, Okwa O, Hunt RH, Ogunrinade AF, Coetzee M. Dynamics of the malaria-vector populations in coastal Lagos, South-western Nigeria. Annals of Tropical Medicine and Parasitology. 2002; 96 (1): 75-82.

21. Onyabe DY, Vajime CG, Nock IH, Ndamss IS, Akpa AU, Alaibe AA, Conn JE. The distribution of M and S molecular forms of Anopheles gambiae in Nigeria. Transactions of the Royal Society of Tropical Medicine and Hygiene. 2003; 97: 605-608.

22. Rousseau DF, Bakare AA, Bankole HS, Julien MC, Doannio MC, Kossou H, Akogbeto MC. Quantification of the efficiency of treatment of Anopheles gambiae breeding sites with petroleum products by local communities in areas of insecticide resistance in the Republic of Benin. Malaria Journal. 2007; 6:56.
23. Sharakhov IV, White BW, Sharakhova MV, Kayondo J, Lobo NF, Santolamazza F, della Torre A, Simard F, Collins FH, Besansky NJ. Breakpoint structure reveals the unique origin of an interspecific chromosomal inversion (2La) in the Anopheles gambiae complex. PNAS. 2006; 103 (16): 6259.

24. Coetzee M, Hunt RH, Wilkerson R, Della Torre A, Coulibally MB, Besansky NJ. Anopheles coluzzii and Anopheles amharicus, new members of the Anopheles gambiae complex. Zootaxa. 2013; 3619(3): 246-274.

25. Sogoba N, Vounatsou P, Bagayoko MM, Doumbia S, Dolo G, Gosoniu L, Traore SF, Smith TA, Toure YT. Spatial distribution of the chromosomal forms of Anopheles gambiae in Mali. Malaria Journal 2008; 7: 205. 